\title{
ERRATUM
}

\section{Erratum to: Clinical and Biological Principles of Cold Atmospheric Plasma Application in Skin Cancer}

\author{
Jesús Gay-Mimbrera · Maria Carmen García • Beatriz Isla-Tejera • \\ Antonio Rodero-Serrano • Antonio Vélez García-Nieto · Juan Ruano
}

Published online: November 25, 2016

(C) The Author(s) 2016. This article is published with open access at Springerlink.com

Erratum to: Adv Ther (2016) 33:894-909

DOI 10.1007/s12325-016-0338-1

Unfortunately, in the original publication of the article, the information regarding PlasmaDerm (CINOGY GmbH) device in Table 1 has been incorrectly published. The table states that the device operates with argon (Gas column), its frequency is DC (Frequency column) and the flow is $8 \mathrm{slm}$ (Flow column).

The online version of the original article can be found under doi:10.1007/s12325-016-0338-1.

J. Gay-Mimbrera $\cdot$ B. Isla-Tejera .

A. V. García-Nieto $\cdot$ J. Ruano ( $\square)$

Instituto Maimónides de Investigación Biomédica

de Córdoba (IMIBIC), Hospital Universitario Reina

Sofía, University of Córdoba, Córdoba, Spain

e-mail: juanruanoruiz@mac.com

M. C. García

Department of Applied Physics, University of

Córdoba, Córdoba, Spain

B. Isla-Tejera

Department of Pharmacy, Hospital Universitario

Reina Sofía, Córdoba, Spain

A. Rodero-Serrano

Department of Physics, School of Engineering

Science of Belmez, University of Córdoba, Córdoba, Spain

A. V. García-Nieto · J. Ruano

Department of Dermatology, Hospital Universitario

Reina Sofía, Córdoba, Spain
However, this information should be changed as the PlasmaDerm (CINOGY GmbH) device operates in ambient air (Gas column), its frequency is AC (Frequency column), and this device is not running any gas flow (Flow column).

Open Access. This article is distributed under the terms of the Creative Commons Attribution-NonCommercial 4.0 International License (http://creativecommons.org/licenses/ by-nc/4.0/), which permits any noncommercial use, distribution, and reproduction in any medium, provided you give appropriate credit to the original author(s) and the source, provide a link to the Creative Commons license, and indicate if changes were made. 